\title{
Educação ambiental: origem e perspectivas
}

Environmental education: origin and perspectives

\author{
Elisabeth Christmann Ramos*
}

\begin{abstract}
RESUMO
Este artigo é uma síntese da dissertação de Mestrado (1993/1996-UFPR). Nosso objetivo foi fazer uma análise crítica da educação ambiental na sua institucionalização histórica e implicações teóricas e sociais. Essa análise inicia-se com a leitura dos documentos oficiais das principais conferenciais internacionais que deram origem a educação ambiental. As categorias de totalidade e interdependência marcaram metodologicamente o trabalho. As concepções de natureza, meio ambiente e ecologia, foram os elementos temáticos tomados como suporte crítico e tornaram-se reguladores para a análise dos equívocos na prática da educação ambiental e dos seus pressupostos epistemológicos.

Palavras-chave: meio ambiente, educação, educação ambiental.
\end{abstract}

\begin{abstract}
This paper is a summary of dissertations (1993/1996-UFPR). Our aim was to do a critically analyse environmental education in its histyorical institutionalization and its theoretical and social implications. We start by reading official documents about the main conferences and international meetings which led to environmental education. Totality and Interdependence marked our research methodologically. Nature, environmental and ecology concept, are the topic elements, which were our critical support, became the regulators of the analyses of the mistakes in enviromental education practice and its epistemological presupposition.
\end{abstract}

Key-words: environment, education, environmental education.

\footnotetext{
${ }^{*}$ Professora da disciplina Biologia Educacional do Departamento de Teoria e Fundamentos da Educação, Setor de Educação da Universidade Federal do Paraná. Licenciada em Ciências Biológicas, mestre em Educação, área de concentração em Recursos Humanos e Educação Permanente.
} 


\section{Introdução}

Diante do reconhecimento mundial da complexidade crescente dos problemas que afetam o meio ambiente, a expressão educação ambiental impregnou não só o ideário político, como também passou a ocupar destaque no contexto pedagógico desde o início dos anos 70. Nas últimas décadas a vinculação da educação ambiental à obtenção de determinados valores, habilidades e atitudes é reconhecida desde a Conferência de Estocolmo/1972, evocando a necessidade de uma consciência "esclarecida" do indivíduo em sua relação com a natureza e o meio ambiente para a sua preservação e conservação. ${ }^{1}$

Inserida no cenário educacional através de propostas e programas internacionais, a educação ambiental passa a servir de suporte teórico e técnico para as atividades que se desenvolvem nesta área, não só para os países desenvolvidos, onde esta intenção brota, mas também no Brasil sem maiores questionamentos, sobretudo, quanto aos seus pressupostos teóricos.

\section{A institucionalização da Educação Ambiental: processo histórico}

Fenômeno característico da segunda metade do século XX, a educação ambiental (EA) surgiu basicamente como uma das "estratégias" da sociedade para fazer frente aos problemas ambientais entendidos, a partir desta época, como ameaças à qualidade e à vida no Planeta. ${ }^{2}$

Os protestos e manifestações questionando os valores da sociedade capitalista e problemas de ordem social e políticas que ocorreram nos anos 50 e 60, criaram um clima favorável para o envolvimento da sociedade civil e impulsionaram o fortalecimento dos movimentos sociais em torno dos quais se agrega e amplia o ambientalismo, e se ergue a bandeira da ecologia. Iniciase uma tomada de consciência crítica de que o crescimento (e por extensão, à sociedade de consumo) ligado aos ideais da razão ocidental burguesa e aos valores da cultura industrial estão associados à destruição do meio ambiente.

Alarmados com os grandes desastres ambientais e os problemas de poluição ameaçando a qualidade de vida, os movimentos de contestação utilizaram a ecologia como um instrumento crítico da civilização industrial. $\mathrm{Na}$ crítica à sociedade moderna capitalista, esses movimentos acreditaram ser

${ }^{1}$ UNESCO. Conferência de Estocolmo. Plano de Ação Mundial. Estocolmo, 1972. In: DIAS, Genibaldo Freire. Educação ambiental: princípios e práticas. São Paulo: Gaia, 1992. p. 272.

${ }^{2}$ UNESCO. Conferência de Tbilisi. 1977. Recomendação 1. In: ESTADO DE SÃO PAULO. Secretaria do Meio ambiente. Educação ambiental e desenvolvimento: documentos oficiais. São Paulo, 1994. p. 31. 
possível uma nova organização da sociedade e de produção econômica voltada não só para uma melhor distribuição da riqueza e uma nova forma de satisfação das necessidades materiais e culturais, como também para uma nova sensibilidade em relação à natureza. A idéia de que a história do homem não pode ser dissociada da natureza, e de que a liberdade do indivíduo deve passar pelo respeito dos "direitos" da natureza, constitui um dos pontos fortes da ideologia contestatória nesse período, vinculada a um ideal de vida natural. Este sentimento ecológico surge junto com a tomada de consciência da vulnerabilidade do mundo moderno suscitado pelo medo das catástrofes, não só de ordem ambiental (acúmulo de poluição, o lixo industrial, as usinas atômicas e os resíduos do lixo atômico) como também de ordem política causada pela ameaça da guerra nuclear e pela corrida armamentista.

Nesse contexto alarmista ocorreu a divulgação do relatório do Clube de Roma. ${ }^{3}$ Apocalíptico, e também polêmico, ele apontava e chamava a atenção para a característica global dos problemas ambientais e o ritmo exponencial de sua evolução caso medidas urgentes não fossem tomadas. Alguns problemas eram cruciais como a ameaça do esgotamento dos recursos naturais, os efeitos da poluição ambiental, o crescimento populacional e o aumento da produção e do consumo. Era preciso impor, portanto, limites tanto para o crescimento e desenvolvimento econômico, como para o crescimento da população, já que os recursos naturais do meio ambiente passaram a ser vistos na sua crescente e ameaçadora finitude. A partir de então, a questão ecológica se impôs na agenda dos governantes dos países desenvolvidos dando início às grandes conferências e eventos internacionais para discutir os grandes problemas ambientais e a elaboração de propostas e estratégias de ação.

Respondendo às preocupações e pressões da sociedade, o governo sueco apresentou na Organização das Nações Unidas uma proposta para a realização de uma Conferência Mundial sobre o Meio Ambiente Humano, o que de fato aconteceu em junho de $1972 \mathrm{em}$ Estocolmo. Foi a primeira vez na história da humanidade que políticos, especialistas e autoridades de governo,

3 Os membros desse Clube estão ligados a grandes indústrias, a órgãos de consultoria (Italconsult), institutos de pesquisa (MIT-Massachusetts Institute of Technology), universidades etc. Na época, o Clube de Roma tinha por objetivo uma "tarefa bastante ambiciosa": elaborar um Projeto sobre o Dilema da Humanidade, o qual foi elaborado a partir de 1970 e publicado em 1972 com o título: The Limits to Growth, sob a responsabilidade de uma equipe de pesquisadores do MIT: Donella H. Meadows, Dennis L.Meadows, Jorgen Randers e William W. Behrens III. A tradução brasileira é de Inês M. F.Litta, publicada pela Editora Perspectiva, São Paulo em 1973. 
representantes da sociedade civil e a ONU, se reuniram para discutir problemas ambientais na qual o meio ambiente foi colocado como tema principal da agenda em uma conferência oficial. Entretanto, as divergências resultantes da diferença no desenvolvimento industrial e econômico entre os dois blocos de países, marcaram posições contrárias dos países do Sul durante a reunião de Estocolmo. ${ }^{4}$

Nesta conferência, observou-se a defesa de perspectivas radicais, com sentidos opostos, embora balizadas por valores preservacionistas e conservacionistas. Uma delas, preocupada com a ameaça da vida humana e dos recursos naturais necessários para manter a qualidade de vida; a outra, preocupada com a destruição das belezas naturais e das espécies animais em extinção. Havia, ainda, a posição criticando o catastrofismo e o alarmismo provocado pelo discurso ambientalista por acreditar que os problemas ambientais poderiam ser resolvidos pelo homem através de medidas técnicas adequadas e, portanto, não deveria interferir no processo de desenvolvimento dos países.

De um modo geral, as questões ambientais foram traduzidas como problemas de poluição do ar, do solo, da água e da escassez dos recursos naturais colocando em risco o bem-estar do homem. Por isso, deveriam ser conservados, com ênfase na necessidade de adotar políticas globais baseada na interdependência planetária de todos os problemas ambientais.

Entre o rol de medidas analisadas, refletidas e recomendadas colocou-se, também, a responsabilidade do ser humano em sua relação com o ambiente, onde a educação adquire importância singular para a solução dos problemas. Manifesta-se a necessidade de mudança na intervenção do meio ambiente, e entende-se que isso é possível pela educação ambiental. Ocorre, assim, o primeiro pronunciamento oficial sobre a necessidade da EA em escala mundial, convertendo-se numa recomendação universal imprescindível, com a propagação de inúmeros projetos e programas para a sua implementação.

A globalização da EA deu um passo significativo com a Conferência Intergovernamental de Tbilisi, realizada em 1977 na Geórgia. Se a Conferência de Estocolmo foi considerada o marco da recomendação mundial sobre EA, a Conferência de Tbilisi ${ }^{5}$ constituiu-se no marco mais

\footnotetext{
${ }^{4}$ A reação de um dos representantes do governo brasileiro resume bem esse confronto: "A pior poluição é a pobreza", e "se o preço do progresso é a poluição que venham poluir o Brasil". CAPOBIANCO, João Paulo. O que podemos esperar da Rio 92? In: São Paulo em Perspectiva. São Paulo: SEADE, v. 6, n. 1 e 2, jan./jun.1992, p. 14.

5 "Participaram da Conferência de Tbilisi, delegados de 68 estados membros da UNESCO, observadores de estados não membros, representantes de organizações intergovernamentais e de organizações internacionais e não governamentais." (DÍAZ, Alberto Pardo. La educacion ambiental como proyecto. Barcelona: ICE, 1995. p. 55)
} 
importante para a definição e evolução da sua institucionalização. Com base nos trabalhos de EA até então realizados, estabeleceu-se uma nova dimensão educativa, determinando prioridades para a sua aplicação. Assim, o documento da Unesco "A Educação Ambiental: as grandes Orientações da Conferência de Tbilisi" converteu-se em referência para os órgãos, pessoas e instituições responsáveis pela EA no âmbito regional, nacional e internacional, constituindo-se num texto técnico com as finalidades, objetivos, princípios orientadores e estratégias para o desenvolvimento da EA.

Nas recomendações de Tbilisi, a EA vincula-se à compreensão de três conceitos fundamentais: aquisição de novos conhecimentos e valores, novos padrões de conduta e a interdependência. Ressalta-se, também, que a EA deve resultar de uma dimensão do conteúdo e da prática educacional, orientada para a preservação e a resolução dos problemas concretos do meio ambiente, através de um enfoque interdisciplinar; levar a compreensão do meio ambiente em sua totalidade e interdependência utilizando o enfoque sistêmico para as questões globais que envolvem o meio ambiente.

Quinze anos depois, realiza-se a Conferência Internacional sobre o Meio Ambiente e Desenvolvimento no Rio de Janeiro em junho de 1992, com o objetivo central de estabelecer acordos, estratégias globais e internacionais, partindo do princípio de que se respeitem "os interesses de todos e se proteja a integridade do sistema ambiental e o desenvolvimento mundial". 6 Toma-se como ponto de partida a desigualdade que se agiganta no mundo, e que traz como consequiência o agravamento da pobreza, das doenças, do analfabetismo e a contínua pauperização dos recursos naturais dos quais dependem o bem-estar da humanidade, e como alternativa se propõem o desenvolvimento sustentável.

Este evento representou, também, um processo pontuado por divergências e interesses contraditórios entre os países ricos e pobres. Ficou notória a falta de compromisso por parte de alguns países do Norte que não assumiram responsabilidades diferenciadas quanto aos recursos financeiros para viabilizar o desenvolvimento sustentável proposto.

Quanto à educação ambiental, o capítulo 36 da Agenda 21 (que recebe esse nome por tratar das estratégias ambientais mundiais para o próximo século) reafirmou as recomendações de Tbilisi ressaltando, que a partir de agora a EA deve dar ênfase ao desenvolvimento sustentável, acrescentando-se assim, mais um novo conceito aos tantos outros introduzidos anteriormente.

${ }^{6}$ CALVO, Susana; CORRALIZA, José A. Educación ambiental: conceptos y propuestas. Madrid: CCS, 1994, p. 64. 
Resumidamente podemos dizer que a educação assume um papel central na construção de um mundo "socialmente justo e ecologicamente equilibrado", condição tida como indispensável para sobrevivência humana e para a manutenção da vida no planeta. A ação individual foi valorizada, as preocupações ambientais da esfera pública para a esfera subjetiva, para o indivíduo, recaindo-se numa visão simplista, na medida em que, o discurso do "sobrevivencialismo" reduz a dimensão política das questões ambientais e procura identificar na ação isolada dos indivíduos as causas da degradação ambiental. E, neste caso, acredita-se que o indivíduo degrada porque ignora e a educação, mais especificamente a educação ambiental, surge como elemento essencial para resolver este impasse. Ou seja, ela deve ser capaz de transformar as relações do homem com o ambiente, entre o indivíduo e a natureza.

Mesmo considerando que existe um consenso global de que o padrão de desenvolvimento baseado no crescimento econômico e degradação ambiental não possa mais ser aplicado, quer por países ricos, quer pelos países pobres, o desenvolvimento sustentável se apresenta como um termo ambíguo e ainda em construção. Entre o reconhecimento comum de que é preciso alterar o modelo de desenvolvimento e a aceitação de uma única forma de desenvolvimento para todos os países, existe um abismo de certa forma intransponível e obstruído pela luta de interesses e conflitos dos vários setores envolvidos como o Estado, as ONGs, os empresários, as Universidades e a sociedade civil. Sem esquecer, também, a palavra dos organismos internacionais, propondo o mesmo tratamento para os países desenvolvidos e para os países em desenvolvimento, sem, entretanto, reconhecer a enorme desproporção entre eles no padrão de consumo, emissão de poluentes, produção de resíduos tóxicos, acesso a novas tecnologias e desenvolvimento econômico.

Num primeiro momento, esses princípios, entre os demais arrolados nos documentos, subsidiaram as propostas e programas de educação ambiental em nível mundial, depois foram sendo incorporados às propostas curriculares de várias Secretarias Municipais e Estaduais aqui no país. A atual lei constitucional brasileira, bem como as estaduais, prescreve o ensino da educação ambiental em todos os níveis escolares fundamentados nos princípios elaborados na Conferência de Tbilisi/1997. Nos últimos anos, essa perspectiva é retomada e referendada nos Parâmetros Curriculares Nacionais com a proposta do meio ambiente como tema transversal, e passou a ser um projeto nacional contido nas palavras de ordem - "educar para o meio" e "a partir do meio" - expressas no documento Parâmetros Curriculares Nacionais 
do MEC (1998). ${ }^{7}$ No entanto, sabe-se que este ensino é precário, eivado de equívocos teóricos e distorções na sua realização prática. E, ainda hoje, a educação ambiental transita sem métodos de ação e avaliação claramente compreendidos e definidos, a despeito de importantes obras publicadas recentemente.

O crescimento mundial do ambientalismo, assim como as recomendações internacionais sobre a EA, seguiu uma evolução contraditória, e não ocorreu de forma linear e homogênea. Pelo contrário, desenvolveu-se em um cenário complexo de forças múltiplas, numa tentativa de transpor e aproximar paradigmas polarizados onde atores com diferentes interesses criam juntos, estratégias e instrumentos muitas vezes antagônicos que se traduziram em ações globais, também contraditórias. Várias são as perspectivas que passam a orientar o discurso de preservação e conservação da natureza representando e reproduzindo um modelo ideológico sob o qual são construídas as políticas e práticas ambientais. Por isto, entendemos que a reflexão sobre os limites e as possibilidades da EA como projeto educacional pressupõe, inicialmente, uma análise crítica das concepções e conceitos teóricos implícitos no tema em questão, explicitando as diferentes posições para que as opções possam ser clara e conscientemente assumidas.

\section{Concepções de Natureza}

Os diferentes períodos da história da humanidade foram marcados por processos diversificados de exploração dos recursos naturais que, simplificando, traduzem maneiras diferentes das sociedades entender e interpretar o mundo. A apreensão material e conceitual de natureza que os homens criam se constitui num dos elementos fundamentais através do qual as relações sociais, a produção material e a cultura de cada sociedade assumem características próprias na sua relação com a natureza.

O breve resumo que apresentamos sobre as concepções de natureza, teve por objetivo não só mostrar diferentes concepções, mas também, e principalmente, destacar o processo de unidade/separação entre o homem e a natureza, e que se manifestam nas diferentes formas de representar a natureza

7 Ver Brasil. Secretaria de educação fundamental. Parâmetros curriculares nacionais: meio ambiente, saúde - ensino de primeira à quarta série e Parâmetros Curriculares Nacionais: apresentação dos temas transversais. Meio ambiente. Brasília: MEC/SEF, 1998. 
que, por sua vez, se expressam nas várias tendências e abordagens da EA no processo da sua institucionalização.

A concepção primitiva de natureza, anterior a dos antigos gregos, desenvolveu-se no sentido da sua compreensão mágica, presente não só nos povos primitivos, como também nas sociedades indígenas ainda existentes. Essa concepção mágica baseia-se numa espécie de analogia entre a natureza e o homem. Ação e sentimentos humanos são transferidos para a natureza, isto é, verifica-se uma espécie de antropomorfização da natureza pela projeção do psiquismo sobre ela.

A natureza, o homem e a sociedade constituem uma unidade que possui vida. A relação entre estas esferas é a da "causalidade mágica", que rege não só as relações dos fenômenos entre eles, mas suas relações com os homens e a relação dos homens uns com os outros. Esta causalidade é possível porque, na relação entre o sujeito e o objeto, entre o fenômeno natural e o psicológico, reina uma espécie de identidade objetiva entre a natureza e o homem.

$\mathrm{Na}$ cosmologia medieval, a separação homem-natureza não determinava dois mundos divididos (o natural e o artificial, alei natural e a lei humana, a necessidade e a liberdade, a matéria e o espírito, o sujeito e o objeto, o corpo e a mente) embora eles fossem perfeitamente discerníveis. A concepção de natureza permanece essencialmente finalista e vitalista. Ela é compreendida como uma totalidade hierarquizada que vai do reino mineral, vegetal, animal, culminando no homem. Nesse conjunto, cada coisa possui um fim determinado e um lugar natural adequado. Cada ser possui sua lei própria: uma ordem natural objetiva ordenada para a realização de fins.

As reelaborações do platonismo e principalmente do aristotelismo (este na filosofia de Santo Tomás de Aquino no século XIII) exerceram influências profundas na concepção e na representação da natureza. Assim, o sentido original e "materialista" da physis para os gregos é substituído por conceitos teológicos da natureza, na medida em que esta é o resultado do ato criador divino e as suas leis a expressão da lei divina. "Perdido o sentido terrestre e material da physis, os padres da igreja latina designaram pelo termo natureza, o conjunto das coisas inanimadas ou vivas que o Deus judaico da Bíblia havia criado nos 7 dias do Gênese." 8

A sua superioridade está no fato de ser criado "à imagem e semelhança de Deus" 9 e de possuir a capacidade (e a liberdade) de se destacar em relação às outras criaturas. Além de possuir superioridade sobre

${ }^{8}$ CASINI, P. As Filosofias da natureza. Trad. Ana Falcão Bastos e Luis Leitão. São Paulo: Martins Fontes, 1975. p. 68.

${ }^{9}$ Santo Agostinho. Confissões, XIII, 47. São Paulo: Abril, 1973. p. 313. 
os demais seres, ao homem é permitido o domínio da natureza, embora com algumas reservas. Na modernidade, com a visão mecanicista, a separação é tão radical que produz duas ordens (substâncias) distintas: a res pensante e a res extensa nos termos cartesianos. Essa produção da natureza como o outro do espírito lança as bases ideológicas para a sua apropriação e dominação e estabelece a cisão radical entre o homem e a natureza. Tal perspectiva foi infinitamente potenciada pelo conhecimento científico e pela instrumentalização tecnológica desse conhecimento, permitindo, na sua apropriação econômica pela sociedade industrial capitalista, a consumação desta separação e o domínio da natureza.

Já na segunda metade do século XVIII, a reação ao mecanicismo registrou, no pensamento de Rousseau, uma valorização da natureza. O naturalismo de Rousseau opera com a hipótese de uma unidade original (vista mais como um princípio do que origem histórica) do homem com a natureza e que a civilização rompe com essa unidade e constrói o homem "artificial". Em oposição ao Iluminismo, Rousseau propõe a tese da decadência da humanidade: o homem é bom naturalmente, pela civilização que ele cria é que ele torna-se mau. "O que há de mais cruel, ainda, é que todos os progressos da espécie humana, afastaram-na, incessantemente, de seu estado primitivo." 10

Por natureza, Rousseau entende não só a origem de uma coisa mas também a sua essência. Natural pode ser tanto aquilo que se origina de um estado de natureza, como aquilo que é verdadeiro, autêntico, não artificial. O estado de natureza é aquele que se supõe, hipoteticamente, ter sido o estado original da humanidade. É um estado pacífico, de paz e harmonia com a natureza, da qual o homem participa íntima e solidariamente, e na qual ele não recebe estímulo para ser mais do que aquilo que ele naturalmente é na solidão primitiva e rude do seu estado de simplicidade (das necessidades e dos instintos) autêntico e não artificial. Esta unidade original propicia uma satisfação imediata e espontânea do homem na natureza. Nesse sentido, a natureza, para Rousseau, tem o significado daquilo que é autêntico, original, não artificial, não fabricado pelo homem. ${ }^{11}$

A tese marxiana para a separação entre o homem e a natureza é vista como conseqüência da análise concreta e histórica que se estabelece entre

${ }^{10}$ ROUSSEAU, J.-J. Discurso sobre a origem e os fundamentos da desigualdade entre os homens. Rio de Janeiro: Rio,1974. p. 31.

${ }^{11}$ No entanto, o naturalismo de Rousseau não significa o abandono da civilização e o retorno à natureza. O Contrato Social parte da situação desnaturada do homem para encontrar uma solução (política) para este estado social. Trata-se de restabelecer não mais uma unidade natural, mas política que se exprime pela idéia de vontade geral. 
ambos. Partindo da relação de metabolismo (Stoffwechsel) entre homem e natureza, pela qual o primeiro se naturaliza e o segundo se humaniza, a natureza separa-se do homem (e passa a ser objeto de utilidade e de dominação exploratória) quando ela se transforma em coisa num processo histórico mais amplo de fetichização da sociedade e do homem produzidos pela forma capitalista de produção de mercadorias. Essa distinção/afirmação entre o homem/natureza significa a impossibilidade de isolar estes termos e de compreendê-los separadamente. Por isso, para Marx, a compreensão da natureza é também a compreensão do homem (e vice-versa) já que é na relação homem-natureza que o homem se transforma a si e a própria natureza. Essa dialética homem/natureza, em que a unidade é o movimento, aparece em diversas obras e fases do pensamento marxista. ${ }^{12}$

A necessária distinção entre o eu (pensamento) e a natureza resulta num distanciamento entre um e outro, presente a partir da concepção mecanicista. O fato dessa separação levar à dominação da natureza, já antevisto por Marx, está no próprio modo como o homem se relaciona com a natureza: ela é objeto de conhecimento para poder ser apreendida, dominada, subjugada.

A pretensão do conhecimento, que põe diante de si um objeto - a natureza - não é neutra, nem inocente. "Pensando, os homens distanciam-se da natureza a fim de torná-la presente de modo a ser dominada." ${ }^{13}$ Esta é a tese de Horkheimer e Adorno que resume a forma como a natureza é, hoje, representada. "O que os homens querem aprender da natureza é como empregá-la para dominar completamente a ela e aos homens." ${ }^{14}$ Para esses autores, o esclarecimento (Aufklärung) não se restringe ao momento histórico do Iluminismo do século XVIII. Constitui, antes, o próprio processo de racionalização da sociedade e a desmistificação do pensamento, o abandono do irracionalismo.

${ }^{12}$ Essa relação dialética homem/natureza afasta Marx da intenção de Engels de separar a história da natureza e de ver nesta última leis dialéticas que são "leis reais de desenvolvimento da Natureza" (A dialética da natureza. 2. ed. Rio de Janeiro : Paz e Terra, 1976. p. 35). Alfred Schmidt critica a posição engelsiana ao afirmar que "enquanto natureza e história estão intimamente entrelaçadas em Marx, Engels vê nelas dois 'domínios de aplicação' distintos do método materialista-dialético [...] a dialética transforma-se naquilo que, de nenhuma maneira, é em Marx: uma cosmovisão, um princípio cósmico positivo". (El concepto de naturaleza en Marx, México : Siglo XXI, 1976, p. 52-53).

${ }^{13}$ ADORNO, T. W. e HORKHEIMER, M. Dialética do esclarecimento. Trad. Guido A . de Almeida. Rio de Janeiro: Zahar, 1985. p. 49.

${ }^{14}$ Ibid., p. 20. 
$\mathrm{O}$ século $\mathrm{XX}$ será o triunfo desse mundo pragmático, com a ciência e a técnica adquirindo, como nunca, um significado central na vida dos homens. A natureza tornou-se cada vez mais um objeto a ser possuído e dominado, e foi subdividida em física, química, biologia entre outras ciências. As ciências humanas se especializaram em economia, antropologia, história, psicologia etc. Qualquer tentativa de pensar o homem e a natureza de uma forma orgânica e integrada torna-se, a partir de então, mais difícil, até porque a divisão não se dá somente no conhecimento. De acordo com Mc Innis, citado por Tanner, a "raiz do nosso dilema ambiental reside no fato de que nós aprendemos a analisar e a pensar o mundo dividindo-o em pedaços. Não aprendemos porém a pensar no mundo juntando-o novamente". ${ }^{35} \mathrm{O}$ paradigma da fragmentação, da divisão, da dicotomia passa a ser cada vez mais característico da sociedade contemporânea.

\section{Conceito de Meio ambiente e Ecologia}

Em relação a educação ambiental, os conceitos de meio ambiente e ecologia se encontram e se entrelaçam como um binômio de importância fundamental, cuja abrangência vem se ampliando conforme ele vai sendo incorporado por diferentes setores da sociedade e áreas do conhecimento com significados diversos. Entre eles, quando o meio ambiente é considerado como sinônimo de natureza. Ou quando ele é confundido especificamente com ecologia e nesse caso, se reduz ao conceito de habitat ou de ecossistemas, ou ainda quando ele é visto apenas como algo exterior ao homem e como fonte de recursos naturais. No caso da ecologia, quando o conceito é usado como possibilidade de organizar e pensar uma visão totalizante, global dos problemas ambientais considerados sob a ótica sistêmica.

Preliminarmente, é possível dizer que a EA está ligada de uma forma mais imediata e "concreta" aos dois aspectos acima mencionados, sobretudo, porque eles estão relacionados com conceitos amplos e complexos incorporados ao projeto de EA. Isto significa dizer que, para compreender-se o sentido da educação ambiental é preciso por às claras e questionar a concepção de meio ambiente que tem prevalecido na sociedade atual e as implicações desta concepção com aquilo que se interpreta e se entende por educação ambiental, problemas ambientais, ou "crise ecológica".

${ }^{15}$ McINN IS, Noel. Apud TANNER, R. T. Educação ambiental. Trad. George Schlesinger. São Paulo: Summus, 1978. p. 31. 
A representação simbólica do meio ambiente é o resultado de uma trajetória histórica que depende não só das condições materiais que cercam cada indivíduo, mas também de conhecimentos e conteúdos afetivos, éticos, ideológicos, filosóficos que condicionam a sua própria percepção.

Nesta perspectiva, o meio ambiente é um conceito chave para o debate das questões ambientais, pois envolve questões de poder, tanto no universo econômico quanto ideológico. Não pode ser visto isoladamente, e tão pouco ser reduzido à sua dimensão biofísica, ou ser tratado segundo os parâmetros da tradição científica e filosófica hegemônica, reproduzindo a dicotomia cartesiana entre o homem e a natureza. Em outras palavras, o meio ambiente não se refere apenas aos aspectos naturais de um lugar, tais como o ar, o solo, a água, a fauna e a flora, mas pressupõe o ser humano e o produto de suas ações. Ao maximizar os efeitos naturais, ao não considerar as repercussões sociais das relações do ser humano com seu ambiente, e ao não problematizar essas relações, reduz-se os problemas ambientais aos problemas de poluição e de destruição da flora e da fauna. Onde e como fica o social e o político?

Se, por um lado, a sociedade tomou consciência de que as questões ambientais tornaram-se nas últimas décadas muito sérias, por outro lado, o discurso ecológico tem sido contraditório frente às decisões políticas e econômicas adotadas. Mesmo considerando que, no discurso e nos programas de ação, o conceito de meio ambiente tem a pretensão de abranger uma multiplicidade de elementos (incluindo-se nele os aspectos naturais, sociais, físicos, econômicos e culturais), uma leitura mais atenta destes discursos, artigos e projetos referentes à questão ambiental possibilita interpretações que revelam um universo potencialmente contraditório em relação a este conceito multifacetado.

O uso do termo ecologia, por sua vez, torna-se popular e seu uso cada vez mais freqüente quando os problemas ambientais se inscrevem no discurso, nos planos e projetos da sociedade moderna. Estabelece-se, a partir de então, um debate não só entre orientações, mas um embate político, referindo-se o termo ecologia a diferentes correntes do pensamento ecológico.

Ao analisar o desenvolvimento do pensamento ecológico, Lago (1988) diz que "o campo da ecologia comporta um bloco heterogêneo de pontos de vista e posições científicas e filosóficas, resultantes de diferentes áreas do pensamento, dotadas de certa autonomia e voltadas para objetos e preocupações específicos". ${ }^{16}$

${ }^{16}$ LAGO, Antonio; PÁDUA, José Augusto. O que é ecologia. 7. ed. São Paulo: Brasiliense, 1988. p. 13. 
A apropriação conceitual do termo pelas outras áreas do conhecimento admite ser a ecologia um novo modelo metodológico, sobretudo nas ciências humanas que manifestam a preocupação de aplicar "modelos ecológicos" para o seu objeto de estudo. Sureda e Colom citam autores que explicam esse fato, dizendo que com "o aparecimento de um marco conceitual de referência diferente do tradicional das ciências sociais, utiliza-se o tratamento teórico da temática própria dos ecossistemas muito humanizados, esse marco é novo enquanto aplica noções da teoria dos sistemas e da cibernética à sociologia, e o conceito de ecossistema ao meio urbano, identificando a problemática ecológica com a problemática sociológica." 17

Segundo estes mesmos autores, uma das razões pelas quais as diversas disciplinas se apropriam da ecologia pode estar no fato de que ela alcançou a condição de uma ciência capaz de produzir conhecimentos globalizantes que estabelecem uma visão de totalidade na qual o universo funciona - de acordo com Lutzemberg - como um "esquema racional integrado". ${ }^{18}$ Contudo, essa apropriação metodológica pode trazer "a suspeita de que a utilização do ecológico por outras disciplinas, responder mais ao modismo que parece desfrutar todo o ecológico do que a sua verdadeira necessidade metodológica." 19 Esse equívoco pode ser semelhante ao produzido por interpretações da ecologia, na qual o homem é reduzido às relações meramente naturais.

Frente a este cenário, qual a tarefa que podemos extrair para a educação ambiental?

\section{Tendências de educação ambiental}

O pressuposto de "formar-se uma consciência ecológica, formar indivíduos com conhecimentos e valores que possibilitem uma relação mais equilibrada e harmoniosa entre o homem e o meio ambiente, trabalhar com as inter-relações e interdependências a partir de um enfoque sistêmico para

\footnotetext{
${ }^{17}$ SUREDA, Jaume; COLOM, Antoni J. Pedagogía ambiental. Barcelona: CEAC, 1989. p. 34.

18 LUTZEMBERG, José, Fim do futuro? Manifesto ecológico brasileiro. Porto Alegre : Movimento, 1976. p. 10.

${ }^{19}$ SUREDA, J.; COLOM, A . J., op. cit., p. 33.
} 
analisar e ordenar os ecossistemas naturais e os humanos, ${ }^{20}$ baseado no elemento teórico-metodológico de ecossistema que, apesar de ser algo suspeito e ambíguo, teve uma influência decisiva no processo de ecologização do pensamento educacional e nas concepções de EA.

Sorrentino classifica as diversas concepções de EA em quatro categorias: a "consevacionista" ligada à biologia voltada para as explicações das causas e conseqüências da degradação ambiental; a "educação ao ar livre" que valorizam o contato direto com a natureza, o retorno à paz e harmonia com a boa natureza; a "gestão ambiental", que segundo o autor, está mais próxima da política e envolve os movimentos sociais e ambientais reivindicando liberdades democráticas e a luta contra a poluição; e a concepção que ele chamada de "economia ecológica" decorrente dos escritos dos anos 70 presentes no pensamento econômico e que tiveram grande influência na atuação dos bancos internacionais e nos documentos produzidos pela Uneso. $^{21}$

Essas concepções de concretizam em diferentes tendências e abordagens da EA. Entretanto elas não são puras nem mutuamente excludentes, o que, aliás, demonstra a dificuldade de classificá-las. $\mathrm{Na}$ prática, algumas se completam, outras se contrapõem. Elas oscilam entre a abordagem naturalista pela idealização da natureza, onde reina a paz e constante harmonia onde o ser humano é o predador, o discurso apocalíptico que tende a criar o imobilismo com informações fragmentadas e descontextualizadas. O discurso que tem o efeito de campanha, privilegiando o imediatismo e não a prática, com grande ênfase no comportamentalismo e morais. Não se trata, entretanto, de negar o que tem sido feito, a superação conceitual implica a incorporação de elementos já construídos. Mas importa, isto sim, avaliar e questionar de como e em que medida o que se faz contribui para alcançar os objetivos propostos.

Compreender e explicitar as possibilidades e os pressupostos pedagógicos de cada uma delas pode ser um instrumento de análise significativo para avaliar aquilo que tem sido proposto para a EA. Diferentes modelos e tendências trazem consigo diferentes interpretações sobre os fins e os propósitos do trabalho educativo e estão sintonizadas com determinadas concepções de natureza, de meio ambiente, de sociedade e de homem. É na interação com este contexto que construímos os parâmetros que orientam o nosso fazer pedagógico.

\footnotetext{
${ }^{20}$ UNESCO, Conferência de Tbilisi, 1977. In: ESTADO DE SÃO PAULO. op. cit., p. 33.

${ }^{21}$ SORRENTINO, M. Formação do educador ambiental; um estudo de caso. São Paulo, FEUSP, 1995, p. 14-18.
} 
Por isso, afirmamos a importantância de compreender-se o desdobramento de conceitos que se oferecem, atualmente, a diferentes usos. Refletir sobre o uso da ecologia no seu enfoque sistêmico, não autoriza a sua aceitação acrítica; assim como, é necessário explicitar os conceitos e concepções utilizadas que, por não ser evidente, suscitam interpretações confusas e equivocadas. Nesse caso, o conhecimento pode ser ideologicamente instrumentalizado no sentido de "naturalizar" os processos políticos de dominação, e ocultar os processos econômicos de exploração decorrentes das relações sociais de produção e das formas de poder que regulam o processo de expansão do capital negando ou mascarando os interesses em conflito.

A educação ambiental não pode limitar-se à explicação de como funcionam os ciclos naturais, restringir-se ao incentivo para que as pessoas amem e respeitem a natureza. Isso, de uma forma ou de outra, já é feito nas escolas há muito tempo. Também não pode pretender, apenas, normatizar o comportamento do homem diante da natureza, anunciando o que pode ou não pode ser feito em relação à natureza. A EA também não se coloca, apenas, como estratégia para a solução dos problemas ambientais, o que talvez, tem sido uma ilusória pretensão.

Tanto o aspecto de se apreender o meio ambiente como uma realidade na sua multiplicidade de aspectos, como o sentido histórico no processo da sua constituição, são elementos fundamentais para se pensar a categoria pedagógica da educação ambiental como um problema teórico. $\mathrm{O}$ meio ambiente não é um conceito estático, pois cada sociedade, no decurso de sua história tem um modo próprio de se relacionar com a natureza e de deixar suas marcas no meio ambiente. Ele não é, em si, um objeto específico para definir uma educação. É importante compreender que a concepção de natureza predominante atualmente na sociedade é um dado histórico. $\mathrm{O}$ que significa admitir a possibilidade de transformação de determinados modelos de interpretação da natureza.

Trabalhar na perspectiva de transformar as relações do homem com a natureza para sua conservação/preservação, como o pretendido, pressupõe compreender que as ações do homem são determinadas pela base material de sua produção que, por sua vez, engendram historicamente as relações sociais, econômicas, políticas e institucionais de uma sociedade. Não é possível, portanto, quando falamos em educação ambiental, excluir ou enfraquecer a complexidade dessa base material que, construída sob o princípio da desigualdade, age de forma desigual sobre os usuários dos recursos naturais.

\section{Considerações finais}


Pensar as origens da educação ambiental como proposta institucional em escala mundial significa muito mais do que realizar um exercício de relatos históricos dos documentos produzidos com esta finalidade. Sobretudo porque as primeiras manifestações sobre as interações entre educação, ambiente e sociedade precedem qualquer documento escrito e se confundem com o ato histórico, pelo qual o olhar europeu se deu conta da necessidade de criar uma "consciência ecológica global". A problemática ambiental não é ideologicamente neutra nem alheia a interesses econômicos, políticos e sociais.

Existe uma relação entre educação e sociedade pela qual interesses econômicos e políticos são projetados sobre a educação. Há de se admitir, portanto, que "a fala que idealiza a educação esconda, no silêncio do que não diz, os interesses que pessoas e grupos têm para os seus usos". ${ }^{22}$

A educação ambiental é antes de tudo uma questão da educação geral, portanto, não pode ser apresentada apenas como uma nova estratégia de ensino sem que sejam questionados os fundamentos, os princípios epistemológicos e conceituais sobre os quais a educação da sociedade atual se desenvolve. A visualização desta perspectiva não permite, pois, a ingenuidade de se defender, quer a escola como simples lugar de transmissão de conhecimentos, quer a escola transformadora da sociedade com o apelo sentimental de salvadora dos problemas, no caso, os problemas ambientais.

Se de um lado, é possível questionar o papel da educação no contexto atual para a formação de uma "nova ética ecológica", por outro lado, é preciso considerar que as necessidades da sociedade atual estão trazendo para o espaço pedagógico imposições que a obrigam a estender o seu campo de conhecimento e atuação em $3 / 4$, caso ele se proponha a contribuir com soluções dentro de uma sociedade cada vez mais fragmentada em seu tecido social e político.

Compreender e desvendar quais são os valores, os mitos e as concepções que estão balizando algumas das expressões cristalizadas no discurso ecológico, e examinar os padrões culturais que interferem no ensino, nas tendências e abordagens da educação ambiental é o desafio que se apresenta para a construção de um projeto de uma educação que seja ambiental.

O debate sobre a questão ambiental, além de questionar os modelos de desenvolvimento e da escolha de modelos, formas e meios de atender às

\footnotetext{
${ }^{22}$ BRANDÃO, Carlos Rodrigues. O que é educação. 3.ed. São Paulo: Brasiliense, 1981. p. 60
} 
necessidades humanas, incorpora também uma reflexão filosófica sobre a natureza da relação que o ser humano estabelece com o seu meio ambiente. Dentro ou fora de qualquer instituição, ele está inserida na vida cotidiana de todos os indivíduos. Para isto é preciso fornecer os meios que auxiliem cada um para melhor formular as perguntas que envolvem o seu entorno, e encontrar uma forma integrada de ler e interpretar o meio ambiente e atuar sobre ele, o que só é possível quando se tem em vista um tipo de questionamento crítico que envolve o próprio homem.

\section{REFERÊNCIAS}

ADORNO, T. W.; HORKHEIMER, M. Dialética do esclarecimento. Trad. Guido A. de Almeida. Rio de Janeiro: Zahar, 1985.

BRANDÃO, C. R. O que é educação. 3. ed. São Paulo : Brasiliense, 1981.

BRASIL. Secretaria de Educação Fundamental. Parâmetros curriculares nacionais: meio ambiente e saúde - ensino de primeira à quarta série. Brasília: MEC/SEF, 1998.

Parâmetros curriculares nacionais: apresentação dos temas transversais. Meio ambiente. Brasília: MEC/SEF, 1998

CALVO, S.; CORRALIZA, J. A. Educación ambiental: conceptos y propuestas. Madrid: CCS, 1994.

CAPOBIANCO, J. P. O que podemos esperar da Rio 92? São Paulo em Perspectiva,

São Paulo: SAEDE, v. 6, n. 1 e 2, p. 13-17, jan./jun.1992.

CASINI, P. As filosofias da natureza. Trad. Ana Falcão Bastos e Luis Leitão. São Paulo : Martins Fontes, 1975.

DIAS, G. F. Educação ambiental: princípios e práticas. São Paulo: Gaia, 1992.

DÍAZ, A. P. La educación ambiental como proyecto. 2. ed. Barcelona: ICE, 1995. 
ENGELS, F. A dialética da natureza. 2. ed. Rio de Janeiro : Paz e Terra, 1976.

ESTADO DE SÃO PAULO. Secretaria do Meio Ambiente. Educação ambiental e desenvolvimento: documentos oficiais. São Paulo, 1994.

LAGO, A.; PÁDUA, J. A. O que é ecologia. 7. ed. São Paulo : Brasiliense, 1988.

LUTZEMBERG, J. Fim do futuro? Manifesto ecológico brasileiro. Porto Alegre: Movimento, 1976.

RAMOS, E. C. Educação ambiental: evolução histórica, implicações teóricas e sociais. Uma avaliação crítica. Curitiba, 1996. Dissertação de mestrado - UFPR.

ROUSSEAU, J.-J. Discurso sobre a origem $e$ os fundamentos da desigualdade entre os homens. Rio de Janeiro: Rio, 1974.

SANTO AGOSTINHO. Confissões, XIII. São Paulo: Abril, 1973

SCHMIDT, A. El concepto de naturaleza en Marx. México: Siglo XXI, 1976.

SORRENTINO, M. Formação do educador ambiental: um estudo de caso. São Paulo: FE-USP, 1995.

SUREDA, J.; COLOM, A. J. Pedagogía ambiental. Barcelona: CEAC, 1989. Texto recebido em 20/04/2001 